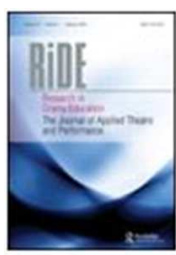

\title{
Performing that which exceeds us: Aesthetics of obscenity and sincerity during 'the refugee crisis'
}

\begin{tabular}{|r|l|}
\hline Journal: & $\begin{array}{l}\text { Research in Drama Education: The Journal of Applied Theatre and } \\
\text { Performance }\end{array}$ \\
\hline Manuscript ID & CRDE-2017-0090.R1 \\
\hline Manuscript Type: & Themed Issue Paper \\
\hline Keywords: & excess, migration, Ai Weiwei, empathy, Fire at Sea \\
\hline \multicolumn{2}{|l}{} \\
\hline
\end{tabular}


'A writing that can be kept or washed away'. As far as my fingertips take me, Royal Court theatre/LIFT (June 2016). Photograph by the author.

\section{$191 \times 191 \mathrm{~mm}(72 \times 72$ DPI $)$}

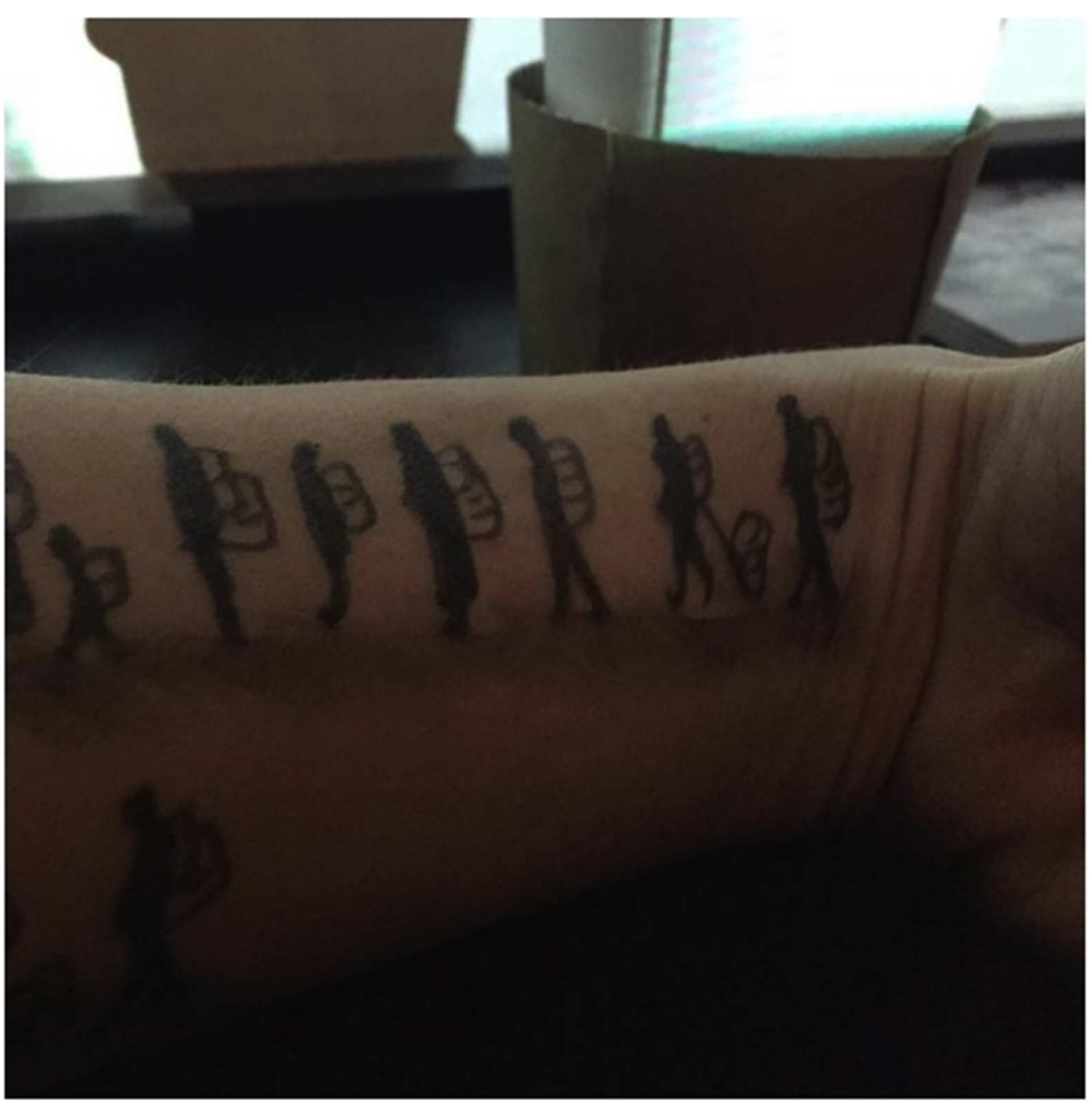




\section{Performing that which exceeds us: Aesthetics of sincerity and obscenity during 'the refugee crisis'1}

I am sitting on a chair. On my left, there is a temporary, white wall with a hole in the middle. On my right, the large window overlooks crowds moving past London's Sloane Square in the early evening of a rainy Saturday in mid June 2016. I am at the Balcony bar of the Royal Court theatre. I am wearing a white robe and headphones. A voice is speaking to me through the headphones. It is the voice of the man who is sitting on the other side of the wall. He is slowly and softly explaining to me what will happen during the next ten minutes, which is the duration of this one-to-one performance. He is asking me to put my arm through the hole. He says that he is a refugee. For the next few minutes, he will draw on my arm while I will be listening to a song about displacement and the loss of home. The English translation of the lyrics is written on the wall to remind the audience member of the crossings, the deaths, the family separations and the longing for home. While the song is playing, the man is using black ink to draw on my arm two lines of people carrying baggage, walking to the edge of my elbow where a clearly defined line seems to mark a border. In the middle of my palm, a tiny boat capsized, is about to sink, while my fingertips are blackened with ink. I am watching him; he is meticulously, softly, though with determination pressing the tip of his black pen and the edge of his brush on my skin. My understanding of what is unfolding is emerging in a space created by the sounds of the song, the sensation of being marked and whatever my eye catches through the window or the hole on the wall. As we are coming to the end of the performance, the man holds my hand; for a moment that feels like a while, we are holding hands, remembering and mourning those who crossed borders and perhaps never arrived. I feel tears on my face. Whatever happened during those ten minutes has exceeded me, surpassed me, and undone me intellectually and emotionally.

As far as my fingertips take me was commissioned for the day-long festival 'On the Move', which was co-produced by the Royal Court theatre and the 2016 London

\footnotetext{
${ }^{1}$ I would like to thank audiences at Canterbury Christchurch University (June 2016), Nottingham Trent University and Freie Universitat, Berlin (October 2016) for their insightful comments and responses to work in progress towards this article.
} 
International Festival of Theatre (LIFT). Developed by London-based, Lebanese live artist Tania el Khoury in collaboration with Basel Zaara, the piece has toured the UK and Europe. In her review, Lyn Gardner (2017) observes that el Khoury's and Zaara's piece 'explores and builds empathy among audiences'. Indeed, As far as my fingertips take me was a tactile and sonic encounter that transformed displacement from a distant event (conjured through images circulated in the public domain) into an indelible experience, just like the clear, material feeling of being written on. A writing that as Zaara said 'can be kept or washed away'. [image 1] Gardner's observation that 'Every time I roll up my sleeves or wash my hands I am confronted by the images and rerun Zaraa's story in my mind. I can't get away from it' captures what is the focus of this article: excess as a key component of contemporary performance in response to migration. In As far as my fingertips take me, the excess emerges through the intense affective encounter between performer and audience member, leaving a (literal and metaphorical) mark at the end. This excessive quality defines this work that, at least for me, exceeded expectations of what a performance about forced migration may feel like for an audience member who has never been exposed to such experiences.

el Khoury's and Zaara's piece provides me with the starting point for this article that aims to consider the relation between the so-called European 'refugee crisis' and the multiple meanings and performances of excess. The focus here is not on work that engages migrants ${ }^{2}$ through participation; for the purposes of this article, I am concerned with how those of us who have not had a direct experience of forced displacement may attempt to cross artistic or conceptual borders to grapple with migration, which I define as that which exceeds us. By exploring examples from different media - theatre, visual arts and film - I aim to analyze the aesthetics, ethics and politics of performance that engages with the figure of the migrant, often instigating intense (emotional and intellectual) reactions from audiences. What are the ways in which audiences witness and respond to the 'pain of others' through artistic practice? To what extent this

\footnotetext{
2 I am using the terms 'migrant' and 'migration' throughout this piece, referring to individuals and collectives who cross the European borders for different reasons: in order to seek asylum, to find work, to build a better life. This is not to dismiss the importance of distinguishing between refugees and other kinds of migrants; however, in the face of rising xenophobia and racist violence against non-white men and women who have crossed borders, it is important not to imply that certain kinds of migrants are 'real', suffer more and are worth protecting more than others.
} 
exposure to work that engages with the pain of others can be read as a way of resisting what Susan Sontag has described as the 'spectacle of suffering', instigating instead a kind of 'political responsiveness' (Butler and Athanasiou 2013: xi)? And what is the role of the artist in a context of crisis, like the one that emerged in the summer of 2015 ?

Before moving on to a discussion of specific examples, it is worth pausing to consider the meaning of the term 'crisis' and the implications of its usage when conceptualizing migration as and through excess. In an interview, where he reflects on the proliferation of austerity policies across Europe and the ideological dimensions of austerity as 'cure', French philosopher Jacques Rancière discusses the interconnection of crisis and excess in the contemporary Western world. He notes that crisis was originally used in medical contexts, signifying the moment of resolution, when a certain diagnosis leads to a particular cure. However, in current language, crisis is associated with pathology. For Rancière, in the aftermath of the 2008 banking collapse and the subsequent financial problems across European countries, the term crisis signifies 'the excessively pathological', obscuring the fact that the very system that the crisis threatens is pathological - in short, the system is always in crisis. He says: 'On the one hand, a crisis is an excess in the logic of the system, the situation of exception which allows drastic measures to be taken [...] But on the other hand this is the normal pathology' (2013:20). For example, the excessive (that is extreme and disproportionate) austerity measures that were introduced mainly in the European South (Greece, Spain, Portugal) since 2010 were put forward as a rational way of curing the excessively pathological economic state of these countries. However, the excessive cure only reproduced the very foundations of the pathology of the system: market deregulation, privatization and extreme labour competitiveness. In this way, crisis - in terms of economy and in this discussion, migration - can be understood as excess in the logic of the system that perpetuates the system.

When naming the ongoing forced displacement of men, women and children due to war, poverty or climate change 'crisis', migration is conceived as excess in the logic of the system that we live in, a system of sovereignty and bordered spaces. In the public domain, migrants are framed as excess (that is unnecessary overload) for sovereign European countries; they exceed and put pressure on existing structures of sustainability and efficiency management, both for individual nation-states and for 
supranational bodies like the European Union (EU). Migration, often described as 'irregular' or 'illegal', is perceived as a pathological condition that can be cured; migrants are framed as superfluous for affluent Western countries. Such arguments, though, neglect key factors - such as the escalation of conflicts, militarization and capitalism - that are cornerstones of the contemporary globalized world and trigger the en masse movement of populations from certain parts of the world. They also neglect that the 'unnecessary', 'illegal' migrants are in fact necessary, cheap labour that helps maintain the existing divisions across the world and class inequalities within specific countries. In the introduction to Border Vigils, journalist Jeremy Harding notes that since the late 1990s asylum applications drastically fell while 'clandestine migration' of low-skilled or unskilled migrants proliferated and, of course, 'there is no provision for “economic migrants" in the Geneva Convention.' (2012: viii) When migration is framed as crisis, excessive, severe measures for curing that pathology are put in place: detention camps, pushbacks of boats, barbed wire fences and legislation that frames the migrant in a perpetual limbo state beyond life and death. But while the sovereign nation-states introduce measures that regulate the terms of who can cross the borders and how, the figure of the migrant still exceeds, spills over and escapes the limits of rationality. Then how can we speak on behalf of that which goes beyond our limits of experience and knowledge? What is the work that representation does in such a context and how does it contribute to shaping attitudes about migration?

In the pages that follow, I propose that certain artistic works that seek to represent that which exceeds the logics of the system, that is migration, are often underpinned by excess. I focus mainly on two examples: Ai Weiwei's responses to the refugee crisis in the island of Lesvos in the North-East Aegean and Gianfranco Rosi's 2016 film Fuoccoamare (Fire at Sea) that engages with everyday life in Lampedusa, a small island off the coast of Sicily that sees numerous arrivals (and deaths) of migrants crossing from Africa. What connects these otherwise very different kinds of performance is that they attempt to capture the consequences of sea crossings as experienced in 'hot spots' of the European South and distribute them to audiences in other symbolic or actual centres of Fortress Europe.

These performances, conceived as protest or documentary, are excessive in terms of the visual grammars they employ, the emotions that they seem to intend to instigate to 
audiences, their politics and ethics. More specifically, these excessive artistic responses to the 'refugee crisis' are defined by two kinds of aesthetics: that of sincerity and that of obscenity. What I wish to propose is that Ai's practice and Rosi's film convey a strong quality of sincerity - or moral urgency - on behalf of the artists; sincerity, though, that is so excessive and occasionally ostensibly naïve that breaches on the borders of the obscene. In my reading, migration presents an excessive conundrum for artists who occasionally seem to be exceeding the borders of their subjectivities, finding themselves in a condition of 'being beside themselves'. ${ }^{3}$ But can we think of a meaningful artistic engagement with the plight of migration unless the artist is moved to the point of excess? That point of excess, which I understand as an exaggerated surplus of emotion that triggers a form of political action, presents some fascinating contradictions and potentialities, which are worth thinking through in more detail. But before I turn my attention to the arts, in the next section I briefly consider how we may approach official EU legislation on migration and asylum as well as languages about migration through notions of excess.

\section{Language, legislation and excess}

According to the UN Refugee Agency (UNHCR), 2015 was 'the year of Europe's refugee crisis', as there were 1,015,078 arrivals (mainly from the Middle East) by crossing the Mediterranean Sea and over 3,700 people went missing or died by drowning, as boats crossed from Turkey to Lesvos. Eighty percent of the migrants arrived in Lesvos, while the majority of men, women and children arriving at the shores of the European periphery were Syrians, Afghanis and Iraqis (Clayton 2015). Obviously, the data attest to the degree of the crisis; however, how can an argument about crisis be built when bearing in mind that there are limited legal ways in which non-Europeans can seek refuge to the European shores? In the Mediterranean Sea, humans become excess weight in overloaded, inflatable boats, which capsize taking them to their death. Those who survive exceed what Europe is purportedly able to accommodate and this leads to

\footnotetext{
${ }^{3}$ I am borrowing the term from the dialogues between Judith Butler and Athena Athanasiou published in Dispossession: The Performative in the Political. There, they develop their argument referring to the social movements that emerged in response to austerity (for example, the Occupy movement or the movement of the squares in Spain and Greece). For the two thinkers, passion and emotion are crucial tools in the current struggles against global injustice.
} 
a perpetuation of the 'crisis' as more migrants undertake perilous journeys in an attempt at escaping or bypassing Europe's border controls. ${ }^{4}$

Migrants seem to exceed the EU legal frameworks; they are framed as irregular, illegal, undocumented, sans papiers. Further, since the summer of 2015, when the so-called 'refugee crisis' gathered pace, the EU has practiced excessive ways of responding to this crisis, that is by going beyond, exceeding international law. In March 2016 the controversial agreement between EU leaders and Turkey to return irregular migrants who crossed the Aegean to Turkey, indicated another way in which the 'solution' to the crisis of migration in Europe exceeds, that is goes beyond the European territory as the management of the migration problem is effectively outsourced. Amnesty International reports describe 2016 as 'Europe's year of shame' (Gogou 2017) since following the agreement, a number of migrants remained stuck in detention camps in the Greek islands (predominantly Lesvos) waiting for a ruling on their asylum applications, because Turkey was considered an unsafe place for refugees. This outsourcing of the management of migration to Turkey may have led to a significant decrease of crossings to Greece but did not translate into an efficient way of relocating migrants from Turkey to other European countries. The agreement confirms not only the persistence of Europe's colonial legacies and the measuring of Europeanness on racial grounds; it also attests to what the UNHCR High Commissioner Filippo Grandi described as 'as much a crisis of European solidarity as [...] a refugee crisis.' (Anonymous 2016)

Against this backdrop of lack of European solidarity and exposure of sharp divisions within the Continent, government officials often used excessive - that is immoderate, pejorative - language. For instance, in 2016, during Prime Minister questions, the then British PM David Cameron referred to men, women and children stuck in the Calais 'Jungle' camp as a 'bunch of migrants'. Cameron's dehumanising statement as well as his reference to 'swarms' of migrants crossing the Mediterranean framed the migrants as excess weight that Britain, 'an incredible place to live' could not accommodate (Elgot 2016). The ostensible inability of the country to accommodate migrants was further exposed when in early 2017 Britain retreated from commitments made under the so-

${ }^{4}$ Indeed, according to data collected by the UNHCR, 2016 was the deadliest year for migrants crossing the Mediterranean Sea, although reports from the region did not dominate international news in the same way they did in the summer of 2015. 
called Dubs scheme, an amendment to the Vulnerable Persons Relocation Scheme, which set out to resettle 3,000 unaccompanied migrant children from other European countries to the UK (Elgot 2017).

That language, which in 2016 transformed into the toxic and hateful discourse of the Leave campaign in the run-up to the referendum on Britain's EU membership, is symptomatic of and reproduces a particular culture that, as Emma Cox (2016) has argued, 'allows [...] systemic refusal or removal by legalised coercion or force' of the unwanted, often dark-skinned migrants. That culture can be analyzed as symptomatic of an excess of sovereignty on behalf of nation-states (both authorities and citizens) who feel that they have the right to dictate who enters the country's territory or not even if they know that such decisions often determine whether someone survives or dies. The excessive language of hate mobilized in the 2016 Leave campaign summarized in the 'Breaking point' UKIP poster that used a photograph of migrants at the Hungarian border - cannot be separated from this excess of sovereignty; the hyperbolic and false arguments put forward prior to the referendum as well as the rise of hate crimes in the period immediately after the Brexit vote demonstrate an excessive and poisonous love for the nation that undoes social cohesion, perpetuating fear and hatred of the migrant Other.

During the LIFT's 'On the Move' festival at the Royal Court, performer and writer Chris Thorpe attempted to tackle this excessive language of love that leads to hate in his durational piece The Milk of Human Kindness. Borrowing its evocative title from Shakespeare's Macbeth, Thorpe's piece mapped contemporary British media attitudes on migration. During the six hours that the piece lasted, Thorpe sat at a desk on the main stage of the Royal Court and relentlessly read a text 'compiled from the comments sections of national newspaper articles on migration, published over the last year or so. [...] Comments were selected according to the user ratings given by the readers of each newspaper.' Thorpe read these comments in a dead-pun, matter-of-fact, soft voice, while the audience could come and go as they pleased. In his note for the festival, Thorpe explains that he took the headlines and comments mainly from three British newspapers: The Sun, The Daily Mail and The Daily Express. He suggests that although these newspapers purport to be offering a space for a necessary conversation about migration, they actually 'provide a forum where something else happens.' The space 
deliberately created by these tabloids - through the constant use of scaremongering headlines and distorted reports or images - is a space of excess and hyperbole, a space where the phrase 'I am not a racist but' functions as a perverse rationalization of hatred aligning the patriots against the 'stranger danger'. The space produced by these newspapers is one of banal nationalism that frames migrants as threat. This banal nationalism often calls for extreme measures on behalf of the state and overtly or not adds to a culture of excessive, extreme sovereignty that perpetuates contemporary necropolitics. Borrowing Sara Ahmed's words from her seminal work on The Cultural Politics of Emotion, the excess that defines these articles, headlines and subsequent comments organizes an affective economy of hate where 'affect is produced as an effect of its circulation.' Such an affective economy of repulsion, rage, loathing and fear is masqueraded as a performance of excessive love: for the people whose voice Thorpe is mediating in The Milk of Human Kindness, it is "because we love, we hate, and this hate is what brings us together' (Ahmed 2004: 43).

The durational form of The Milk of Human Kindness is excessive for both audience members and the artist. For how long can a (most likely) liberal, left-wing audience member subject themselves to languages of overt or covert racism and xenophobia? Towards the end of the piece, Thorpe's voice was breaking because of exhaustion, laughter or despair in response to the arguments put forward in the newspapers. But as Andrew Haydon suggests in his review (2016), '[t]he tiredness, the exhaustion, the occasional flickers of exasperation or personal feeling all felt a vital, inextricable component of the whole'. All these elements can be approached as a performance of excess in the sense that Butler and Athanasiou read the state of 'being beside oneself' as a step towards political responsiveness. Programmed alongside pieces that engaged with the migrant through empathy, The Milk of Human Kindness staged an attempt at engaging with those voices, who express no empathy and instead attack the purported excess of political correctness (often referred to as 'political correctness gone mad') for the 'lenient' policies towards migrants. These voices, excessive and extremely hostile, saturate and often set the tone of public debate; Thorpe's sincere attempt at engaging with them involved a form of theatrical excess, which may be a necessary tool for approaching (or even understanding) that which we are not. In the next example I 
discuss an instance where this excess takes an even more explicit form, which was described as obscene.

\section{Ai Weiwei's Safe Passage (2016): Aesthetics of obscenity}

The piles of life vests often found on the beaches of Lesvos are another performance of migration as excess. Numerous photographs during the summer of 2015 captured those remains of the tool that the migrant body needed to cross the sea - en masse, these life vests function as a poignant reminder of the migrant embodying what Zygmunt Bauman has described as 'human waste' or 'wasted humans', 'the excessive and redundant' (2004: 5). Each one of the life vests stands in for the person who is no longer there and who remains invisible, having perished while crossing or having chosen other forms of invisibility as they attempt to arrive to their final European destination. What happens, though, when that excess of wasted life vests works as primary material for a piece of art that is located and framed away from the shores of the Mediterranean? In February 2016, Chinese visual artist Ai Weiwei moved 14,000 life vests from Lesvos to Berlin's Konzerthaus during the Berlin Film Festival. For his installation Safe Passage, Ai used the life vests to wrap the columns of the $19^{\text {th }}$ century, neoclassical building while a black rubber rescue boat hanged over the entrance. The life vests and the boat highlighted the absence of the migrant body, gesturing to Europe's ongoing complicity in the deaths of migrants at sea. As Joseph Pugliese (2009) has noted in his piece on Australian and Italian systems of maritime migration and incarceration, the migrant body interrupts the European tourist's spaces of leisure - like the beach - as different modalities of life and death co-exist in that space. Similarly, the excessive piles of life vests utilized as primary materials for Ai's protest artwork interrupt a space of tourism and leisure designed for consumption in Berlin, the symbolic centre of Fortress Europe. ${ }^{5}$

Inside the building, the Cinema for Peace Gala, a lavish reception-fundraiser for refugees, orchestrated by the artist, was held. Numerous actors and celebrities wore emergency thermal blankets and a number of photographs of a sea of 'golden thermal

${ }^{5}$ Safe Passage is reminiscent of another public art installation project that was mounted in a monumental space in Berlin. In 2009, Greek visual artist Kalliopi Lemos presented At Crossroads in front of the Brandenburg Gate; the sculpture was made of boats-relics of crossings of the Aegean and it made a powerful statement about the absence of the migrant body in the symbolic centres of Fortress Europe. For more on the politics and ethics of Lemos's sculptural trilogy on migration, see Zaroulia 2015. 
blankets' circulated via social media. The transition from the exterior of the building that was covered by the life vests (the excess of death) to the extravagant reception (the excess of wealth) that took place inside the building overwhelmed and troubled audiences. Berlin's Culture Secretary Tim Renner expressed his reservations about this protest performance; although he found the Safe Passage installation-response to the terror of migrant deaths 'not subtle but justified', he commented that the act of guests of the Gala donning metallic emergency blankets 'even if considered an act of solidarity, it certainly has an obscene element' (quoted in Loughrey 2016). Renner seems to suggest that the juxtaposition produced by the pairing of the installation and the Gala charity event offended moral codes; the Gala was particularly considered gratuitous, an act of pure theatre.

The use of the term 'obscene' is particularly interesting from a theatrical point of view; it suggests that what should have been kept off-stage (presumably, the figure of the migrant-victim) has now been moved onstage, but not in an authentic way. It suggests that the Gala's guests, professional actors - who are paid to pretend, to perform a role momentarily pretended to be migrants, wearing the blankets. Were these celebrities, white-skinned, affluent men and women, pretending to be what they are not, just like in a fancy dress party or a film? Was the Cinema for Peace Gala an exaggerated performance of empathy or a self-indulgent, excessive performance of guilt? Or, even, did Ai stage the Gala in an attempt at exposing the inadequacy of celebrity activism, the good-intended sincerity and empathy, which do not translate in meaningful action against injustice? Is there any parallel between Thorpe's honest attempt at engaging with anti-migrants' excess of racism and xenophobia and Ai Weiwei's spectacular protest, this excessive and ambiguous performance of sincerity?

In the artist's words, his engagement with the plight of migrants in Lesvos through a series of projects captures his desire to be 'an artist trying not just to watch events but to act' (Tan 2016). ${ }^{6}$ This attempt to act, rather than simply watch, had reached its climax

\footnotetext{
${ }^{6}$ Around the same time, Ai Weiwei closed his exhibition 'Ruptures' in Copenhagen in protest to the Danish government's decision to confiscate valuable from refugees seeking asylum. Apart from making work inspired by the crisis and having exhibitions in Amsterdam and Athens, the artist was also filming footage (approximately 600 hours) for the documentary Human Flow that was released in autumn 2017. Safe
} 
a few weeks before the Berlin installation, when Ai had reproduced for the magazine India Today one of the indelible images of summer 2015, the lifeless body of Alan Kurdi lying on the beach in Bodrum, Turkey. For that image-replica of one of the most 'haunting' photographs of the 2015 refugee crisis, the artist posed in the same way with the dead boy, lying face down on a beach in Lesvos. Conceived as a way of calling for 'dignity for the refugees' and as protest challenging the avalanche of images of refugees circulated in the public domain, that performance intervention aimed to pay tribute not only to Kurdi but to all the unnamed victims of the crossings; however, it caused a huge backlash. The replica was seen as excessive, outrageous, unnecessary and undesirable; according to his critics, the artist produced a 'crass, lazy' work, producing a selfindulgent image that was disrespectful of the dead boy and edging on hubris. Writing for The Guardian, Jonathan Jones (2016) names the work an 'egotistical stunt'; in openDemocracy (2017), the replica image is described as 'an unfortunate collision of an "incredibly important artist" and the "hopelessness of the people".' All critics of Ai Weiwei overwhelmingly agree that this was not the right way of responding to the crisis, as the image placed too much emphasis on the artist, rather than the refugees. Certainly, the image shocks or feels jarring, interrupting what is considered an ethical representation of the Other; its excessive qualities (an older, alive man pretending to be a little, dead boy) distance the viewer. However, Ai's performance remains ambiguous, since the sincerity, the honest moral urgency that underpins the work is such that undoes empathy and can provoke other ways of thinking.

Jones accuses Ai for 'emotional colonialism' and 'narcissism', suggesting that the best works of the Chinese artist are the ones that he does not feature in. Jerome Phelps, in a piece with the evocative title 'Why is so much art about the "refugee crisis" so bad?' considers whether Ai depoliticises the refugee crisis by performing empathy, which accentuates the human dimensions of perishing at sea rather than the complex structures that perpetuate the uneven distribution of mobility - and consequently, experiences of life and death. Following Phelps's argument, Ai's work (particularly Berlin's Gala) captures a tendency that is common among artists, celebrities and occasionally activists: one can 'feel good' about oneself by momentarily pretending that

Passage should be understood in this wider context of prolific work in response to the refugee crisis. 
they are that which they are not - for instance, by donning an emergency thermal blanket or by lying face down on the beach. Hence, Phelps, like Jones, seems to suggest that removing oneself from the image or the artwork is necessary for any true and ethical engagement with the plight of the migrant.

However, I would argue that any possibility of political responsiveness emerges from the controversial presence of the individual (artist or activist) in the image. This presence draws attention to the limitations and failures of representation, or, to borrow Phelps's terms, recognizes the 'inadequacy of the passive contemplation of yet more images of refugees.' More importantly, beyond what can be rejected as naval-gazing, theoretical debates about the nature of representation and its shortcomings, the presence of the artist in the image highlights the inadequacy of citizens of sovereign nation-states that perpetuate injustice; we may be there empathizing but we fail to act. ${ }^{7}$ Ai Weiwei's replica image does not only commemorate Alan Kurdi and the numerous other victims of crossings; it invites us to reckon with our own failures by staging a failed attempt at empathizing with the Other, by attempting to move beyond (exceeding) the borders of our subjectivities. The image-replica shows the artist in relation to the migrant, 'being beside oneself, taken out, given over, moved and moving' (Butler and Athanasiou 177). This kind of artwork certainly does not alter the power hierarchies that maintain injustice but, affectively, it attests to bodily vulnerability and dispossession; that kind of recognition, I would argue, is the first step towards a politics of contesting the precarious conditions of living (and dying) of other bodies.

Despite the ethical shortcomings of Ai's works, in the face of the obscenity of excessive circulation of hate, or the obscenity of the unaccounted deaths of nameless men, women and children, wouldn't an obscene performance like the Gala for Peace, where the excessive number of emergency thermal blankets appear like golden outfits, constitute an act of transgression? If migration exceeds our limits of rationality and reason, it follows that performances that engage with migration should also interrupt the logic or expectations of the European sovereign I. Public interventions such as British actor

\footnotetext{
${ }^{7}$ An analogy can be drawn here with other controversial performances of exile and asylum as those discussed as 'hyper-authentic' by Silvija Jestrovic (2008). In the examples that Jestrovic discusses, the asylum-seeker performs herself in a hyperauthentic manner, thus calling attention to her condition of exploitation and opening up a space for intervention, beyond the artistic community.
} 
Benedict Cumberbatch's urge to audiences at the Barbican, London to 'fuck the politicians' and help the migrants in Lesvos perform an excessive moral urgency and sincere desire to 'do something' on behalf of the artist. Works like Ai's installation, diein protests at the beaches of Brighton or activist performances like Centre of Political Beauty's The Dead are Coming where the bodies of dead migrants were purportedly exhumed from mass graves in South Europe and transported to their burials in Berlin retain that excessive quality of the obscene, which seeks to make an intervention in a genuine, almost naïve and ostensibly inappropriate manner. In the final section of this article, I consider this notion of the sincere obscene, or the obscene as a surplus of sincerity by exploring a film that focuses on the everyday - only to make the juxtaposition with the migrants' deaths even more acute.

\section{Aesthetics of Sincerity: Fire at Sea (Fuoccoammare; 2016)}

Even if they were bringing the bodies of dead migrants ashore a few minutes from where you live, you'd still brew up coffee and cook dinner with the radio on. Your kids would still do their homework and get to school in the morning. Life would go on. Not necessarily oblivious to the crisis unfolding on your doorstep, but existing at some remove from it. (Johnston 2016)

These are the words that open Trevor Johnston's review of Italian documentary-maker Gianfranco Rosi's award-winning Fire at Sea. The film presents the slow and somewhat distant lifestyle of Lampedusan citizens, while the tragedy unfolds off the island's shores. Towards its end, the film features some harrowing scenes, shot on board of a migrant boat but mainly, it tells the story of young Samuele, a boy who spends most of his time trying to shoot birds with his sling shot. The boy develops a 'lazy eye' that he is trying to cure throughout the film; a subtle yet clear metaphor for Europe's myopic outlook on the pain of others. Rosi presents a mesmerizing yet desolate landscape, as he films Samuele and his friend riding through the rocky roads of the rugged countryside against the backdrop of the sea - a sea that is glorious, furious, silver and grey, impervious to human tragedies and border politics.

Thus, the film tells the story of two worlds. On the one hand, the everyday life of Lampedusan inhabitants: fishermen mending their nets; grandmothers cooking pasta; housewives looking after their households listening to sentimental Sicilian songs played 
in the local radio station. On the other hand, the agonizing voices of the coastguard and rescue teams repeating 'Your position, please, my friend your position' as they are trying to locate the boats with the migrants; the dehydrated and broken, burnt bodies of the migrants; Lampedusa's only doctor giving a compelling account of the work that he is required to do to save migrant lives, born and unborn. The two worlds seem largely separate but the film, for all its poetic and poignant qualities, fails to address the reasons that may lead to this separation of worlds: the EU legislation, policing, the role of the military in the management of the crisis. In the introduction to a special issue on 'Lampedusa and Cultural Expressions', Federica Mazzara (2016) argues that Lampedusa is 'a site of tension' as it receives numerous migrants who cross from Africa as well as international tourists. According to Mazzara, Fire at Sea fails to capture the complexity of experiences in Lampedusa: migrants are deprived of voice and mainly 'they appear in their misery: dirty, exhausted people' while 'the documentary does not recognize the strong resistance by locals to the "spectacle of the migrant crisis"' and the ways in which the mainstream narrative about Lampedusa is often challenged. Indeed, the representation of Lampedusan citizens seems occasionally stereotypical and when the film is distributed in other European countries, it runs the risk of perpetuating divisions between the civilized North and the crude South European periphery.

Notwithstanding the validity of certain arguments that Mazzara is putting forward, my contention with her critique is that the film is not 'dragging the viewer to compassion and pity' in a simplistic way. Instead, what the film does effectively is to ask the question: what do we see when we encounter images of migration? How do we look and how do we see all these images that are circulated in excessive manners? How seeing that which exceeds us, often framed in obscene ways make us - to borrow the terms from Joe Kelleher's recent study on The Illuminated Theatre - 'hold the image', 'suffer the image', 'receive its transmission, bearing amongst us its infinitesimal weight and motion' (2014: 3)? The images in Fire at Sea leave a mark: the woman crying having realised that she is the survivor but that others have not made it; the face of a man who was beaten up so badly that his tears are bloody; the excessive mass of corpses trapped in the boat's hold (where the third class is travelling having paid 'only' \$800). Of course, as Sontag (2001) has argued, to see images of suffering 'does not necessarily strengthen conscience and the ability to be compassionate'; like I argued in the previous section, $\mathrm{Ai}$ 
Weiwei's practice follows Sontag's observation. In Fire at Sea, the excessive reaction that I have been concerned with throughout this article does not emerge only from images of suffering; it mainly emerges from the juxtaposition of the images of suffering with the excess of the banal and ordinary. The viewer suffers the pain of the invisible others differently when immediately after the scenes of migrants' rescue, she is confronted with scenes such as the one when an Italian housewife carefully makes the bed before she kisses the Madonna and the saints in a performance of oblivious blissful ignorance or perhaps, even, guilty complacency. That excess of the everyday constitutes the obscene in Fire at Sea and works in similar ways to the excess of celebrities wearing the emergency thermal blankets in the Cinema for Peace Gala.

Rosi has explained that his process involves him filming alone and this creates a 'close intimacy' with what he is filming. For example, half way through the film, a group of male migrants from Nigeria are caught praying in a form blending a hymn and rapping verse; 'it is risky in life not to take a risk because life itself is a risk', they say. Their words are not addressed to us; we just happen to hear them. There are of course some key ethical questions about how Rosi managed to film distressed and traumatised migrants; did he get their consent? How? When? Do we have the right to see the images that we do? The first time we encounter the migrants in the film is when they are moved from their boat to land; they disembark the coastguard boats and are given emergency blankets before they have to get on a bus and are moved to a detention centre. During that first transport, still at sea, a man looks back at the camera that somehow has found its way under his emergency blanket that hides him from the rays of sun. The migrant looks back at me, the viewer; the gaze of the migrant pricks me in a way that is indelible. A few times during the film, the migrants look back at the camera perhaps wondering what the camera is doing there, adding another filter in their burdened 'arrival'. According to Johnston, Rosi 'makes no pretence that pointing a camera at them [i.e. the migrants] will magically allow us to bridge that gulf of consciousness between them and us.' However, this intimate way of filming is perhaps the ultimate form of performing sincerity, putting forward an open invitation to the migrant to look back at us and for us to have to reckon with that gaze. It is an excessive intimacy that bears the potential of reversing the power structure that maintains migration and its mainstream representation. 
It is that excessive intimacy that also underpinned the performance that I discussed at the start of this article. The tears that I felt at the end of As Far as my fingertips take me were the result of an excess of intimacy; even though I did not meet the gaze of the man on the other side of the white wall, the sentiment I experienced was comparable to that generated by Rosi's film, particularly in the moments that the migrants look back at the camera. What were those tears at the end of the performance at Royal Court theatre? A mixture of empathy, solidarity and rage for the injustices of the contemporary world, those tears - sincere and cathartic - captured my helplessness and failure. This was an incomplete and insufficient, yet powerful moment of 'being beside oneself', an instance of 'affective alliance' (Butler and Athanasiou 187) with the one that is dissimilar to me. Phelps concludes his article about 'bad art' made about refugees, suggesting that what is needed in contemporary art about migration is spatial reorientation, new ways of mapping the shifting hierarchies of our world. In As Far as my Fingertips take me, a performance devoid of images but full of song, the affluent here and the dispossessed there got conflated, leaving the audience member, undone and moved, to consider their role in this division.

In this article, I have tried to think through how performing migration often involves aesthetics of excess, obscenity and sincerity. On the basis of examples discussed here, the more sincere the intentions, the more excessive are the results. What we perform, as artists and as audiences, is a condition that goes beyond us; unless we encounter the foreigness of that condition, we will fail to move past our sense of identity, belonging, roots and routes. Moments, like the example I started this article with, when I was holding Basel's hand in the Balcony bar of the Royal Court, during a festival that was dedicated to empathy, are

affective moments - at once all-powerful and powerless - [They] do not arise in order to be deciphered or decoded or delineated but, rather, must be nurtured [...] into lived practices of the everyday as perpetually finer-grained postures for collective inhabitation. (Gregg and Seinworth 2010: 21)

Works like Thorpe's Milk of Human Kindness, Ai Weiwei's practice and Rosi's Fire at Sea further nurture such 'powerful and powerless' moments, moving beyond empathy 
towards the realm of political responsiveness through the ambiguous and controversial performance of excess. 


\section{List of References}

Ahmed Sara. 2004. The Cultural Politics of Emotion. London and New York: Routledge. Anonymous. 2016. ' 6 steps towards solving refugee situation in Europe' UNHCR: UN Refugee Agency http://www.unhcr.org/uk/news/press/2016/3/56d957db9/unhcr-6steps-towards-solving-refugee-situation-europe.html

Bauman, Zygmunt. 2004. Wasted Lives: Modernity and its Outcasts. Polity Press.

Butler, Judith and Athena Athanasiou. 2013. Dispossession: The Performative in The Political. London: Polity Press.

Clayton, Jonathan. 2015. 'Over one million sea arrivals reach Europe in 2015' UNHCR:

The UN Refugee Agency

http://www.unhcr.org/news/latest/2015/12/5683d0b56/million-sea-arrivals-reacheurope-2015.html

Cox, Emma. 2016. 'To Permit Refusal' Contemporary Theatre Review Interventions 26.4 https://www.contemporarytheatrereview.org/2016/to-permit-refusal/

Elgot, Jessica. 2017. 'Government defeats attempt to restart Dubs scheme' The Guardian https://www.theguardian.com/uk-news/2017/mar/07/government-defeats-attemptto-restart-dubs-scheme

Elgot, Jessica. 2016. 'How David Cameron's language on refugees has caused anger' The Guardian https://www.theguardian.com/uk-news/2016/jan/27/david-cameronsbunch-of-migrants-quip-is-latest-of-several-such-comments

Gardner, Lyn. 2017. 'Bristol festival leaves its mark to audiences with personal, political shows.' The Guardian Theatre Blog https://www.theguardian.com/stage/theatreblog/2017/feb/13/bristol-festival-inbetween-time?CMP=share btn tw

Gogou, Kondylia. 2017. 'The EU-Turkey deal: Europe's year of shame.' Amnesty International https://www.amnesty.org/en/latest/news/2017/03/the-eu-turkey-dealeuropes-year-of-shame/

Gregg, Melissa and Gregory Seinworth. 2010. The Affect Theory Reader. Duke University Press.

Harding, Jeremy. 2012. Border Vigils: Keeping Migrants out of the Rich World. London: Verso.

Haydon, Andrew. 2016. 'The Milk of Human Kindness/ Royal Court/LIFT.' http://postcardsgods.blogspot.gr/2016/06/the-milk-of-human-kindness-on.html 
Jestrovic, Silvija. 2008. 'Performing like an asylum-seeker: paradoxes of hyperauthenticity', Research in Drama Education: The Journal of Applied Theatre and Performance 13.2: 159-70.

Johnston, Trevor. 2016. 'Review of Fire at Sea'. Sight \& Sound.

Jones, Jonathan. 2016. 'Ai Weiwei is making a feature film. I'm worried.' The Guardian https://www.theguardian.com/artanddesign/jonathanjonesblog/2016/may/03/aiweiwei-feature-film-refugee-crisis

Kakogianni Maria and Jacques Rancière. 2013. 'A precarious dialogue', Radical Philosophy 181 (September/ October 2013), pp. 18-25.

Kelleher, Joe. 2014. The Illuminated Theatre: Studies on the Suffering of Images.London and New York: Routledge.

Loughrey, Clarisse. 2016. 'Ai Weiwei made a room full of celebrities take selfies in refugee emergency jackets', The Independent http://www.independent.co.uk/artsentertainment/art/news/ai-weiwei-made-a-room-full-of-celebrities-take-selfies-inrefugee-jackets-a6881266.html

Mazzara, Federica. 2016. 'Lampedusa: Cultural and artistic spaces for migrant voices.' Crossings: Journal of Migration and Cultures 7.2. pp. 129-34.

Phelps, Jerome. 2017. 'Why is so much art about the "refugee crisis" so bad?' openDemocracy https://www.opendemocracy.net/5050/jerome-phelps/refugee-crisisart-weiwei

Pugliese, Joseph. 2009. 'Crisis heterotopias and border zones of the dead.' Continuum: Journal of Media and Cultural Studies, pp. 663-79.

Sontag, Susan. 2001. On Photography. New York: Picador

Tan, Monica. 2016. 'Ai Weiwei poses as drowned Syrian refugee boy in "haunting" photo.' The Guardian https://www.theguardian.com/artanddesign/2016/feb/01/aiweiwei-poses-as-drowned-syrian-infant-refugee-in-haunting-photo

Zaroulia, Marilena. 2015. 'At the Gates of Europe: Sacred Objects, Other Spaces and Performances of Dispossession.' Performances of Capitalism, Crises and Resistance: Inside/Outside Europe. London: Palgrave Macmillan. pp. 193-210. 